\title{
Porcine Dorsal Root Ganglia Ovarian Neurons Are Affected by Long Lasting Testosterone Treatment
}

\author{
B. JANA ${ }^{1}$, K. PALUS ${ }^{2}$, K. MELLER ${ }^{1}$, J. CALKA ${ }^{2}$ \\ ${ }^{1}$ Division of Reproductive Biology, Institute of Animal Reproduction and Food Research of the \\ Polish Academy of Sciences, Olsztyn, Poland, ${ }^{2}$ Division of Clinical Physiology, Faculty of \\ Veterinary Medicine, University of Warmia and Mazury in Olsztyn, Olsztyn, Poland
}

Received March 8, 2016

Accepted August 5, 2016

\section{Summary}

We studied the effect of testosterone overdose on the number, distribution and chemical coding of ovarian neurons in the dorsal root ganglia (DRGs) in pigs. On day 3 of the estrous cycle, the ovaries of both the control and experimental gilts were injected with retrograde tracer Fast Blue. From day 4 of the estrous cycle to the expected day 20 of the second studied cycle, the experimental gilts were injected with testosterone, while the control gilts received oil. After the completion of the protocol the Th16-L5 DRGs were collected. Injections of testosterone increased the testosterone ( $\sim 3.5$ fold) and estradiol-17 $\beta$ ( $\sim 1.6$ fold) levels in the peripheral blood, and reduced the following in the DRGs: the total number of the Fast Blue-positive perikarya, the population of perikarya in the L2-L4 ganglia, and the numbers of $\mathrm{SP}^{+} / \mathrm{CGRP}^{+}, \mathrm{SP}^{+} / \mathrm{PACAP}^{+}, \mathrm{SP}^{+} / \mathrm{nNOS}^{+}$and $\mathrm{SP}^{-} / \mathrm{nNOS}^{+}$perikarya. In the testosterone-injected gilts, the populations of $\mathrm{SP}^{+} / \mathrm{CGRP}^{-}$, small and large androgen receptorsexpressing perikarya were increased. These results suggest that elevated androgen levels during pathological states may regulate the transmission of sensory modalities from the ovary to the spinal cord, and antidromic regulation of the ovarian functions.

\section{Key words}

Testosterone • Dorsal root ganglia • Ovarian neurons • Gilts

\section{Corresponding author}

B. Jana, Division of Reproductive Biology, Institute of Animal Reproduction and Food Research of the Polish Academy of Sciences, 10-748 Olsztyn, Tuwima 10, Poland. Fax: +48 89535 74 21. E-mail: b.jana@pan.olsztyn.pl

\section{Introduction}

It is well recognized that the mammalian ovary receives neuronal inputs from the sympathetic, parasympathetic and sensory components of the peripheral nervous system (PNS). In pigs, the sensory ovary-projecting neurons (referred to further as ovarian perikarya or ovarian neurons) occur in the dorsal root ganglia (DRGs) neuromers from Th10 to L5. Studies on the chemical nature of DRGs ovarian neurons in pigs revealed that they are immunoreactive (IR) to substance $P$ (SP), calcitonin gene-related peptide (CGRP), galanin (GAL), pituitary adenylate cyclase-activating polypeptide (PACAP), neuronal isoform of nitric oxide synthase (nNOS), somatostatin (SOM), vasoactive intestinal peptide (VIP) and tyrosine hydroxylase (TH) (Jana et al. 2012, Majewski et al. 1997, Majewski et al. 2002). Previously, it was indicated that ovarian-related afferent nerves, besides their basic function of the transmission of sensory modalities from the ovary to the spinal cord, also play an essential role in local mechanisms of folliculogenesis and vascular tone regulation in the gonad (based on the phenomenon of antidromic nervous stimulation) (Majewski 1997).

There are data concerning the influence of sex steroids on the morphological and chemical plasticity of PNS neurons supplying the urogenital targets. Regarding the androgens, it has been shown that androgen receptors (AR) are expressed in perikarya of the pelvic ganglion (PG) (Keast and Saunders 1998, Purves-Tyson et al. 2007) and DRGs (Keast and Gleeson 1998) in male rats. Moreover, the AR-positive PG neurons contained VIP, 
TH or nNOS (Keast and Saunders 1998, Purves-Tyson et al. 2007, Schirar et al. 1997), and viscera-supplying lumbar and sacral afferent neurons simultaneously expressed AR and CGRP (Keast and Gleeson 1998). Androgens changed the morphology of viscera supplying PG neurons (Keast and Saunders 1998) and the chemical phenotype of neurons in the hypogastric ganglion (Hamill and Schroeder 1990) and in the PG (Löffter et al. 2004). These effects are believed to be important for many reproductive behaviors in males, as well as in urinary bladder and lower bowel functions (Kanjhan et al. 2003). It is also known that AR occur in the developing DRGs of sheep fetuses of both genders (Luo et al. 2008), and also that androstenedione acting by these receptors localized in the celiac ganglion neurons may mediate a luteotropic effect in rats during late pregnancy (Vallcaneras et al. 2009) and after parturition (Vallcaneras et al. 2011).

Hyperandrogenism is one of the most common endocrine disorders of adult women, and can result from many pathological states. The ovary is the main source of androgens in women with polycystic ovary syndrome (PCOS) (Panidis et al. 2005) and idiopatic hyperandrogenism, while increased adrenal androgen secretion is prevalent in non classic 21-hydroxylase deficiency (Carmina 2006). Augmentation in peripheral blood androgen levels is found in patients suffering from adrenal hyperplasia (Goodarzi et al. 2003) and ovarian (Singh et al. 2012) and adrenal androgen-secreting tumors (Varma et al. 2013). Extensive production of androgens takes place in pigs with uterine inflammation (Jana et al. 2004) and polycystic ovaries (SzulańczykMencel et al. 2010), and in dogs with adrenal dysfunction (Hill et al. 2005).

Studies on the influence of androgens on the PNS neurons supplying the reproductive organs of domestic animals are very limited. In fact, the pig, due to its embryological, anatomical and physiological similarity to humans, constitutes an especially valuable species for bio-medical research, including that of ovary functions (Swindle et al. 2012, Szulańczyk-Mencel et al. 2010). We previously presented that long-term testosterone treatment altered the morphological and immunochemical organization of the caudal mesenteric ganglion (CaMG) (Jana et al. 2013b), the sympathetic chain ganglia (SChGs) (Jana et al. 2015) and the paracervical ganglion (PCG) (Jana et al. 2014) ovarian neurons in adult gilts. We hypothesize that augmented concentrations of androgens during pathological states can also change the number, distribution and chemical coding of ovarian neurons in the DRGs. In support of this, we studied the total number and distribution of ovarian perikarya, visualized by intraovarian injection of the neuronal retrograde tracer Fast Blue (FB), and the numbers of FB-labeled ovarian perikarya expressing SP and/or CGRP, GAL, PACAP, nNOS, as well as AR in the DRGs of long-term testosterone-treated adult gilts.

\section{Materials and Methods}

\section{Animals and experimental procedures}

Six crossbred (Large White x Landrace) gilts, aged 7-8 months and weighing 90-110 kg, with at last two regular estrous cycles were used in this experiment. The estrous-showing behavior was detected using a boartester. Three days before surgical operations the gilts were transported from a farm to a local animal house and kept in individual stalls under natural light and temperature (April, May). They were fed a commercial grain mixture and tap water ad libitum. The study procedures were approved by the Local Ethics Committee, University of Warmia and Mazury in Olsztyn (Agreement no 21/N).

On day 3 of the first studied estrous cycle (day 0 of the experiment) median laparotomies were performed under general anesthesia induced by azaperone ( $2 \mathrm{mg} / 1 \mathrm{~kg}$ of body mass, Stresnil, Janssen Pharmaceutica N.V., Belgium) and sodium pentobarbital $(30 \mathrm{mg} / 1 \mathrm{~kg}$ of body mass, Vetbutal, Biowet, Puławy, Poland) in all gilts to expose the ovaries. After an abdominal incision, the right and left ovaries were exposed after gentle removal of the surrounding tissues, and a $5 \%$ solution of fluorescent retrograde neuronal tracer FB (EMSCHEMIE GmbH, Germany) was applied to each ovary. The right and left sides of the organ were injected 5 times (10 $\mu$ l of the dye solution per 1 injection, with a total volume of $100 \mu \mathrm{l}$ per ovary) using a Hamilton syringe equipped with a 26-gauge needle, keeping a similar distance between the sites of the injections. To minimize the diffusion of the tracer into surrounding tissues (e.g. bursa ovary, mesosalpinx, oviductal infundibulum) the needle was left in situ for at least 4 min after each injection, and there after the injection area was subsequently rinsed with isotonic saline and gently wiped with gauze. In all gilts a polyvinyl cannula (outer diameter $2.2 \mathrm{~mm}$, inner diameter $1.8 \mathrm{~mm}$, Tomel, Tomaszów Maz., Poland) was also inserted into the jugular vein in order to collect blood samples. 
The gilts were randomly assigned to one of two groups: a control group (group I, $\mathrm{n}=3$ ) and the experimental group (group II, $\mathrm{n}=3$ ). In the gilts of group I, from day 4 of the first studied estrous cycle (day 1 of the study) to the expected day 20 of the second studied cycle (i.e. for 38 consecutive days), $2 \mathrm{ml}$ of oil were injected i.m. every $12 \mathrm{~h}$ (at 07:00 and 19:00 h). In the gilts of group II, at the same time and in the same manner $1000 \mu \mathrm{g}$ of testosterone (Cat. \# 35800, Serva Electrophoresis $\mathrm{GmbH}$, Germany) in $2 \mathrm{ml}$ of corn oil were injected. The applied dose of testosterone was determined based on our preliminary experiment showing that its application increases the peripheral blood testosterone concentration about 3.5 fold. To estimate the levels of testosterone, androstendione, estradiol-17 $\beta$ and estrone, blood samples were collected from gilts of both groups $1 \mathrm{~h}$ before the first testosterone/oil injection (at 6:00 h, day 1 of the study) and throughout the whole period of testosterone/oil injection (twice a day at 09:00 and 21:00 h, days 1-38 of the study). The samples were then immediately placed in an ice bath, where they were kept until centrifugation $\left(10 \mathrm{~min}, 1500 \times \mathrm{g}\right.$, at $\left.4{ }^{\circ} \mathrm{C}\right)$. The plasma was decanted and stored at $-20^{\circ} \mathrm{C}$ until further processing. The analysis of daily concentrations of androgens and estrogens in the peripheral blood of gilts was described earlier (Jana et al. 2013b). The concentrations of these hormones before testosterone/oil injection on day 1 of the study and on day 38 are presented in Table 1. After the last testosterone/oil injection the gilts were deeply re-anesthetized (following the same procedure as applied prior to the laparotomy) and perfused transcardially via the ascending aorta with $4 \%$ paraformaldehyde in $0.1 \mathrm{M}$ phosphate buffer (PB; $\mathrm{pH}$ 7.4). After perfusion the bilateral CaMG, $\mathrm{SChGs}$ from Th16 to S2, the uterine cervix with PCG, and the bilateral DRGs (along with spinal cord segments Th16 to L5) were removed, postfixed by immersion in the same fixative for $10 \mathrm{~min}$, then washed with $0.1 \mathrm{M} \mathrm{PB}(\mathrm{pH}$ 7.4) over two days and finally transferred to and stored at $4{ }^{\circ} \mathrm{C}$ in $18 \%$ buffered sucrose solution ( $\mathrm{pH} 7.4$ ) containing $0.01 \%$ natriumazide. The tissues were then kept at $-80^{\circ} \mathrm{C}$ until further processing. Data concerning the morphology and immunochemical structural organization of the CaMG (Jana et al. 2013b), SChGs (Jana et al. 2015) and PCG (Jana et al. 2014) in testosterone-injected gilts were published earlier.

\section{Immunohistological procedures}

Frozen ganglia were cut in a cryostat (Frigocut, Reichert-Jung, Nussloch, Germany) into $10-\mu \mathrm{m}$ thick
Table 1. Mean ( \pm SD) levels of testosterone, estradiol-17 $\beta$, estrone and androstenedione in the peripheral blood $(\mathrm{pg} / \mathrm{ml})$ on day 1 of the study before first injection of oil in the control gilts and testosterone injection in the experimental gilts, and daily levels of these hormones on day 38 of the study after oil/testosterone injection.

\begin{tabular}{|c|c|c|}
\hline & $\begin{array}{c}\text { Day } 1 \\
\text { before } \\
\text { oil/testosterone } \\
\text { injection }\end{array}$ & $\begin{array}{c}\text { Day } 38 \\
\text { after } \\
\text { oil/testosterone } \\
\text { injection }\end{array}$ \\
\hline & \multicolumn{2}{|c|}{ Testosterone } \\
\hline \multirow{3}{*}{$\begin{array}{l}\text { Control } \\
\text { Testosterone } \\
\text {-treatment }\end{array}$} & $35.2 \pm 6.46$ & $24.8 \pm 12.6$ \\
\hline & $29.7 \pm 8.33$ & $89.1 \pm 33.15^{* * *}$ \\
\hline & \multicolumn{2}{|c|}{ Estradiol-17 $\beta$} \\
\hline \multirow{3}{*}{$\begin{array}{l}\text { Control } \\
\text { Testosterone } \\
\text {-treatment }\end{array}$} & $7.17 \pm 1.3$ & $17.2 \pm 2.35$ \\
\hline & $8.5 \pm 2.04$ & $14.5 \pm 4.99$ \\
\hline & \multicolumn{2}{|c|}{ Estrone } \\
\hline \multirow{3}{*}{$\begin{array}{l}\text { Control } \\
\text { Testosterone } \\
\text {-treatment }\end{array}$} & $17.1 \pm 5.07$ & $15.66 \pm 1.29$ \\
\hline & $2.8 \pm 1.3$ & $5.5 \pm 0.85^{*}$ \\
\hline & \multicolumn{2}{|c|}{ Androstenedione } \\
\hline Control & $45.13 \pm 8.3$ & $40.2 \pm 18.7$ \\
\hline $\begin{array}{l}\text { Testosterone } \\
\text {-treatment }\end{array}$ & $38.6 \pm 11.9$ & $1.36 \pm 21.8$ \\
\hline
\end{tabular}

$* \mathrm{P}<0.05$, *** $\mathrm{P}<0.001$ - indicate differences between both groups for the same hormone/time sample collection.

sections and mounted on chrome alum-coated slides. With the use of an Olympus BX51 microscope (Olympus, Poland), equipped in epi-illumination fluorescence microscopy (V1 module: excitation filter $330-385 \mathrm{~nm}$, barrier filter $420 \mathrm{~nm}$ ), the occurrence of retrogradely FB-labeled neurons was checked in serial sections of the bilateral ganglia. Sections with FB-labeled perikarya were processed for a routine double-labeling immunofluorescence technique to estimate SP and/or CGRP, GAL, PACAP, nNOS immunoreactivity, and for a routine single-immunofluorescence technique to determine AR (Majewski and Heym 1991). After airdrying at room temperature (rt) for $45 \mathrm{~min}$ and rinsing in $0.1 \mathrm{M}$ phosphate-buffered saline (PBS; pH 7.4; $3 \times 10 \mathrm{~min})$ the sections were incubated in a blocking buffer containing: $10 \%$ of normal goat serum (MP Biomedicals, USA), in $0.1 \mathrm{M}$ PBS, $0.1 \%$ donkey serum (Abcam, UK), $1 \%$ Triton X-100 (Sigma-Aldrich, USA), 
$0.05 \%$ Thimerosal (Sigma-Aldrich, USA) and $0.01 \%$ $\mathrm{NaN}_{3}$ for $1 \mathrm{~h}$ (rt) to reduce non-specific background staining. Subsequently, after another wash in PBS ( $3 \times 10 \mathrm{~min})$, the sections were incubated overnight (rt) with primary antisera raised against SP (rat monoclonal, AdD Serotec, Cat. \# 8450-0505, UK, 1: 700) and/or CGRP (rabbit polyclonal, Millipore, Cat. \# AB5920, USA, 1: 8 000), GAL (rabbit polyclonal, Peninsula Lab., Cat. \# T-4326, USA, 1: 8 000), PACAP (rabbit polyclonal, Peninsula Lab., Cat. \# T-4465, USA, $1: 15000$ ) and nNOS (rabbit polyclonal, Chemicon Internationl a Serogicals Company, Cat. \# AB5380, USA, $1: 15000)$. Following subsequent rinsing in PBS (3 x $10 \mathrm{~min}$ ), co-expression of SP/CGRP, SP/GAL, SP/PACAP and SP/nNOS was visualized by incubation with fluorescein isothiocyanate (FITC)-conjugated goat anti-rat IgG (Cat. \# 112-035003, Jackson Immunores. Lab., USA, dilution 1: 800) and with biotinylated goat anti-rabbit IgG (Cat. \# AP132B Chemicon, UK, diluted $1: 1000)$ and then with CY3-conjugated streptavidin (Cat. \# 016160084, Jackson Immunores. Lab., USA, dilution $1: 9000)$ for $1 \mathrm{~h}(\mathrm{rt})$. The ganglional sections with FB-labeled perikarya were also incubated with antisera against the AR (polyclonal rabbit anti-rat, N-terminus, Cat. \# 1358-P1, NeoMarkers Fremont, CA, USA, dilution $1: 250$ ). To visualize the primary antibody, sections were incubated with biotinylated goat anti-rabbit IgG (Cat. \# AP132B Chemicon, UK, diluted $1: 1000)$ and then with CY3-conjugated streptavidin (Cat. \# 016160084, Jackson Immunores. Lab., USA, dilution $1: 9000)$ for $1 \mathrm{~h}(\mathrm{rt})$. Next, the washed sections were cover-slipped in carbonate-buffered glycerol ( $\mathrm{pH}$ 8.6). Control slides were processed as described, but without incubation with the primary antibody. Retrogradely labeled/immunostained neurons were analyzed and photographed with the appropriate filter sets for FITC (B1 module, excitation filter 450-480 nm, barrier filter $515 \mathrm{~nm}$ ) and CY3 (G1 module excitation filter $510-550 \mathrm{~nm}$, barrier filter $590 \mathrm{~nm}$ ). All SP- and/or CGRP-, GAL-, PACAP-, nNOS-, AR-IR as well as all retrogradely labeled cell bodies were counted in every fourth section of the bilateral DRGs. Only neuronal profiles with a visible nucleus were scored to avoid double counting. Pictures were digitalized and analyzed with Analysis software (version 3.02, Soft Imaging System, Munich, Germany). The diameter of a particular neuron was determined by acquisition software, and the data were used to divide ovary-projecting neurons into three size-classes: small (average diameter up to $30 \mu \mathrm{m}$ ), medium-sized (diameter 31-50 $\mu \mathrm{m}$ ) and large (diameter $>51 \mu \mathrm{m}$ ) cells (Bossowska et al. 2009). The distribution of all ovarian perikarya was evaluated in cranial, caudal, ventral, dorsal and central regions of the DRGs. During light microscopic analysis the area located in the middle part of each DRG was defined as the central region. Consequently, the dorsal, ventral, cranial and caudal regions were defined respectively. Particular regions displayed similar areas.

\section{Statistical procedures}

To calculate the mean $( \pm$ SD) total numbers of ovarian perikarya, the numbers of different size-classes of perikarya and total numbers of AR-expressing cells, data gained from six control and six hyperandrogenized DRGs, were averaged per one DRG for each group, and then the mean $( \pm \mathrm{SD})$ total numbers between both groups were compared by Student's $t$-test. For calculation of the statistical significance in mean $( \pm$ SD) numbers of the neuronal sets (in particular ganglia and regions, with different chemical coding, expressing AR) a one-way analysis of variance (ANOVA) followed by a NewmanKeuls test was chosen. Differences with a probability of $\mathrm{P}<0.05$ were considered significant.

\section{Results}

The number and distribution of ovarian perikarya in the $D R G s$

After treatment with testosterone the total number of ovarian perikarya in the DRGs Th16-L5 was lower $(\mathrm{P}<0.01)$ than in the control ganglia $(75 \pm 17.3 \mathrm{vs}$. $152.3 \pm 41.1$, respectively). Testosterone application led to a decrease $(\mathrm{P}<0.05)$ in the number of medium perikarya as compared to the control group $(24.7 \pm 16.7$ vs. $55.7 \pm 32.7$, respectively). The populations of small and large perikarya were similar in the control and testosterone-treated gilts $(21.7 \pm 11$ vs. $19.1 \pm 13.4$, $33.75 \pm 22$ vs. $28.6 \pm 13.5$, respectively). After testosteronetreatment a reduction in the population of ovarian perikarya in the L2 $(\mathrm{P}<0.001)$, L3 $(\mathrm{P}<0.01)$ and L4 $(\mathrm{P}<0.05)$ ganglia, as well as a lack of perikarya in the Th16 ganglion, were revealed. The number of ovarian perikarya in the central region of the DRGs Th16-L5 was lower $(\mathrm{P}<0.05)$ in the testosterone-treated gilts than in the control ones. The populations of perikarya in particular ganglia and ganglional regions of the DRGs of both groups are depicted in Figures 1 and 2, respectively. 

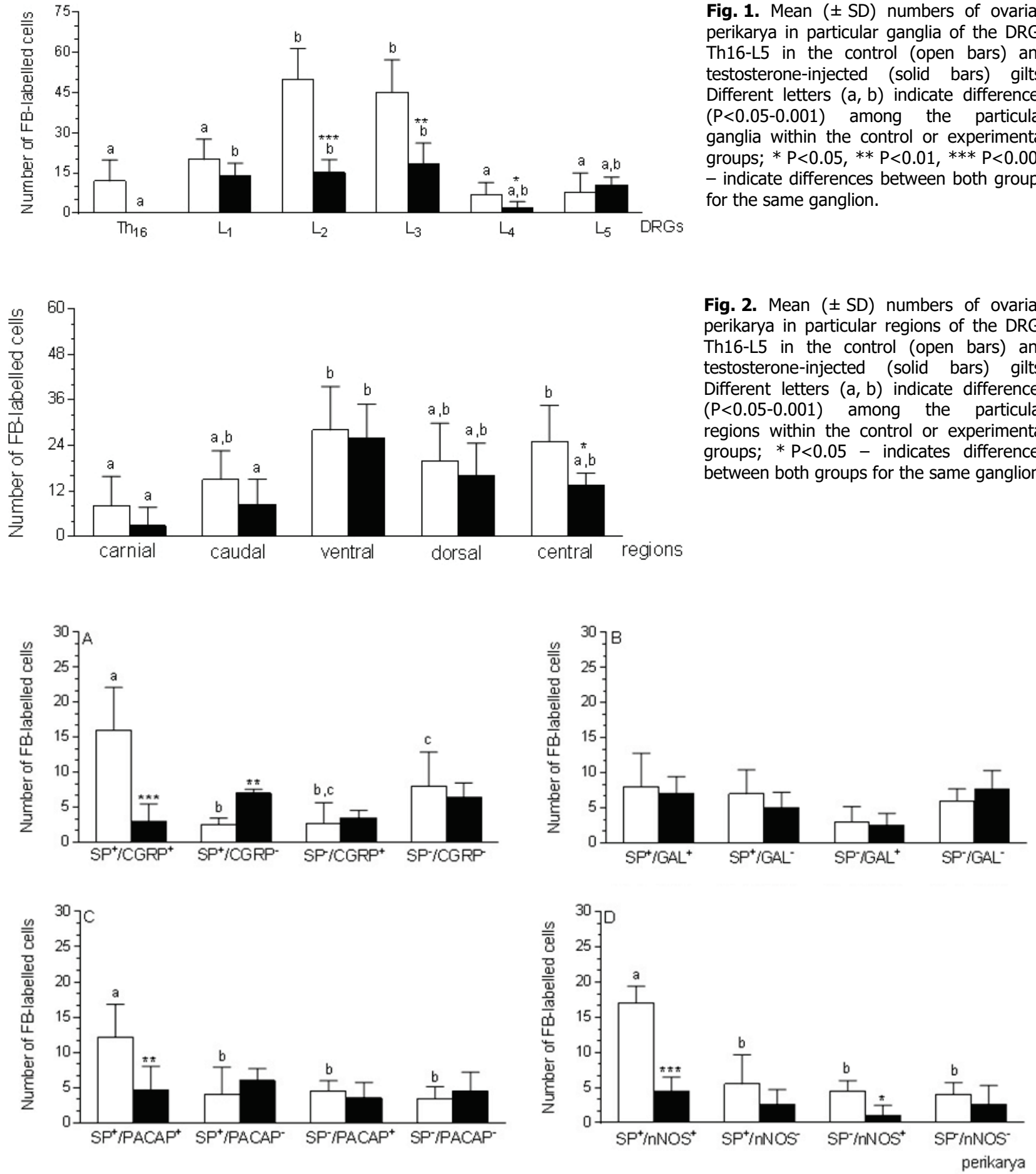

Fig. 1. Mean ( $\pm S D$ ) numbers of ovarian perikarya in particular ganglia of the DRGs Th16-L5 in the control (open bars) and testosterone-injected (solid bars) gilts. Different letters $(a, b)$ indicate differences $(P<0.05-0.001)$ among the particular ganglia within the control or experimental groups; * $\mathrm{P}<0.05, * * \mathrm{P}<0.01, * * * \mathrm{P}<0.001$ - indicate differences between both groups for the same ganglion.

Fig. 2. Mean ( \pm SD) numbers of ovarian perikarya in particular regions of the DRGs Th16-L5 in the control (open bars) and estosterone-injected (solid bars) gilts. P $<0$ letters $(a, b)$ indicate differences regions within the control or experimental groups; * $\mathrm{P}<0.05$ - indicates differences between both groups for the same ganglion.

Fig. 3. Mean ( \pm SD) numbers of ovarian perikarya immunoreactive to SP and/or CGRP (A), SP and/or GAL (B), SP and/or PACAP (C) and SP and/or nNOS (D) as well as immunonegative to the above-mentioned substances in the DRGs Th16-L5 of the control (open bars) and testosterone-injected (solid bars) gilts. Different letters $(a, b, c)$ indicate differences $(P<0.05-0.001)$ among the particular neuronal populations within the control group; $* \mathrm{P}<0.05$, ** $\mathrm{P}<0.01$, *** $\mathrm{P}<0.001$ - indicate differences between both groups for the same neuronal population.

The number of ovarian perikarya containing $S P, C G R P$, GAL, PACAP and nNOS in the DRGs

In all studied DRGs, injections of testosterone led to a drop $(\mathrm{P}<0.001)$ in the number of $\mathrm{SP}^{+} / \mathrm{CGRP}^{+}$ perikarya, and to an increase $(\mathrm{P}<0.01)$ in the number of 
significantly changed (Figs 3B and 4I-P). In the DRGs of testosterone-injected gilts the number of $\mathrm{SP}^{+} / \mathrm{PACAP}^{+}$ perikarya was lower $(\mathrm{P}<0.01)$ than in the control group, and $\mathrm{SP}^{+} / \mathrm{PACAP}^{-}, \quad \mathrm{SP}^{-} / \mathrm{PACAP}^{+}$and $\mathrm{SP}^{-} / \mathrm{PACAP}^{-}$ populations did not statistically differ in either group (Figs 3C and 5A-H). Treatment with testosterone also resulted in a decrease in the populations of $\mathrm{SP}^{+} / \mathrm{nNOS}^{+}$ $(\mathrm{P}<0.001)$ and $\mathrm{SP}^{-} / \mathrm{nNOS}^{+}(\mathrm{P}<0.05)$ perikarya, while numbers of $\mathrm{SP}^{+} / \mathrm{nNOS}^{-}$and $\mathrm{SP}^{-} / \mathrm{nNOS}^{-}$perikarya were similar in both groups (Figs 3D and 5I-P). The numbers of ovarian perikarya containing SP and/or CGRP, GAL, PACAP, nNOS as well as those devoid of the abovementioned substances within the DRGs of the control and testosterone-treated gilts, are presented in Figures 3A-D.
The number of ovarian perikarya expressing AR in the $D R G S$

The total number of perikarya containing AR in the DRGs Th16-L5 of testosterone-injected gilts was higher $(\mathrm{P}<0.05)$ than in the control ganglia $(28.38 \pm 12.7$ vs. 18.2 \pm 3.6 , respectively). The populations of small $(\mathrm{P}<0.001)$ and large $(\mathrm{P}<0.05)$ perikarya expressing $\mathrm{AR}$ were increased in testosterone-affected ganglia, while populations of AR-positive medium perikarya did not statistically differ in either group (Fig. 6 and Figs 7A-F). No labeling of AR was observed when the primary antibodies were omitted (Figs 7G-I). The numbers of ovarian perikarya expressing AR, as well as those devoid of this receptor within the ganglia of both groups, are given in Figure 6.
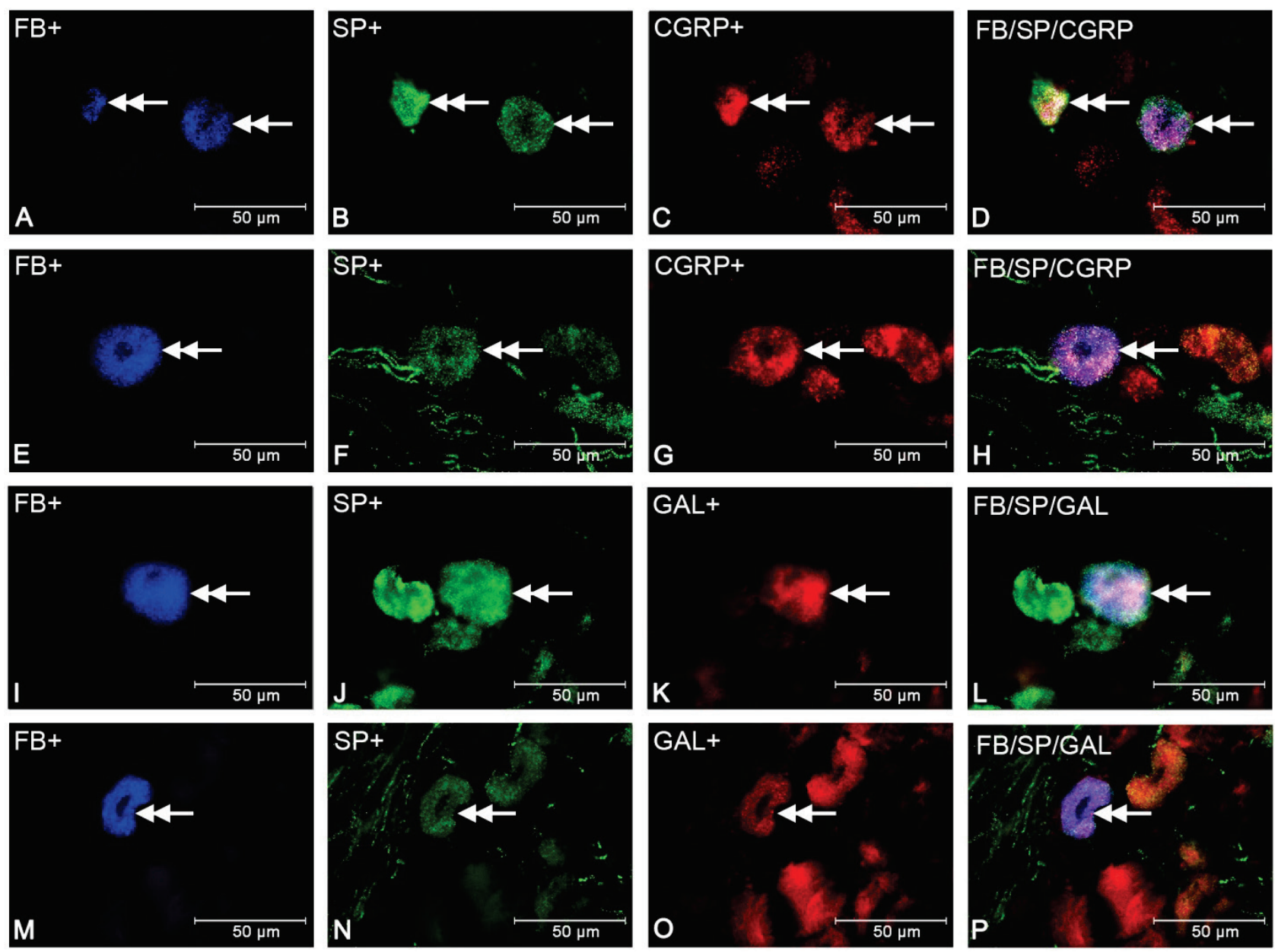

Fig. 4. Fluorescent micrographs showing SP- $(\mathbf{B}, \mathbf{F}, \mathbf{J}, \mathbf{N}), \operatorname{CGRP}-(\mathbf{C}, \mathbf{G})$ and $G A L-(\mathbf{K}, \mathbf{0})$ immunoreactivity in the DRGs of the control $(\mathbf{A}-\mathbf{D} ; \mathbf{I}-\mathbf{L})$ and testosterone-injected (E-H; $\mathbf{M}-\mathbf{P})$ gilts after injections of FB into the ovaries. The double arrow indicates FB-positive ovarian perikaryon containing the two examined substances. Photographs $D, H, L$ and $P$ have been created by digital superimposition of three color channels; FB-positive (blue), SP-positive (green), and CGRP- or GAL-positive (red). Two perikarya immunoreactive to SP and CGRP visible in the L3 ganglion of the control gilt (A-D). Note in the testosterone-injected gilt, only one perikaryon immunoreactive to these substances is present in $\mathrm{L} 3$ ganglion $(\mathrm{E}-\mathrm{H})$. In the DRG $\mathrm{L} 2$ of the control $(\mathrm{I}-\mathrm{L})$ and testosterone-injected (M-P) gilts is present one perikaryon expressing SP and GAL. 

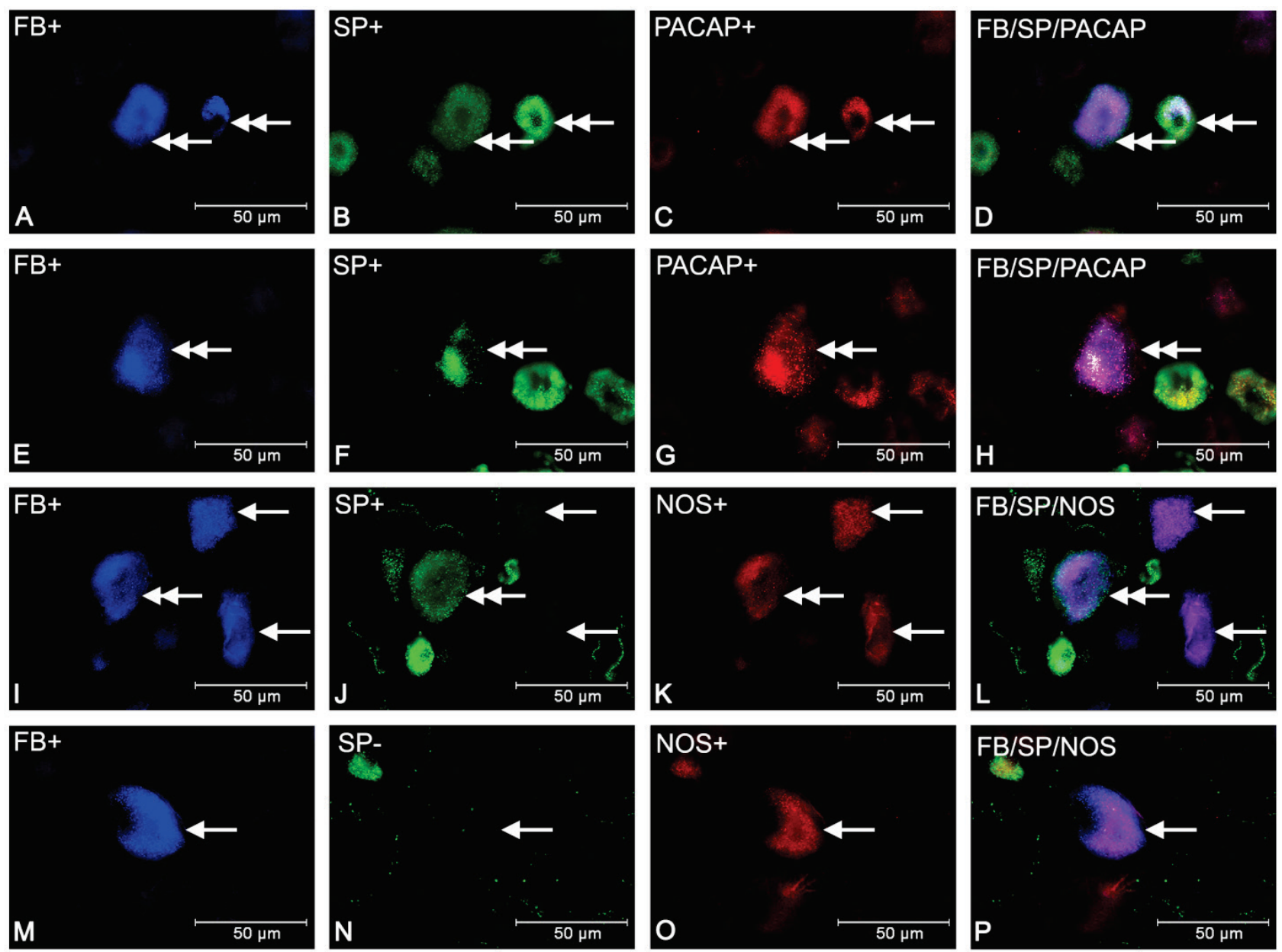

Fig. 5. Fluorescent micrographs showing SP- $(\mathbf{B}, \mathbf{F}, \mathbf{J}, \mathbf{N})$, PACAP- $(\mathbf{C}, \mathbf{G})$ and nNOS- $(\mathbf{K}, \mathbf{0})$ immunoreactivity in the DRGs of the control (A-D; I-L) and testosterone-injected (E-H; M-P) gilts after injections of FB into the ovaries. The double arrow indicates FB-positive ovarian perikaryon containing two examined substances. The arrow shows FB-positive ovarian perikaryon containing one of the two examined substances. Photographs $\mathrm{D}, \mathrm{H}, \mathrm{L}$ and $\mathrm{P}$ have been created by digital superimposition of three color channels; FB-positive (blue), SP-positive (green), and PACAP or nNOS-positive (red). In the L3 ganglion of the control gilt visible two perikarya positive to SP and PACAP (A-D). Note in the testosterone-injected gilt, the drop in the number of perikarya containing SP and PACAP in L3 ganglion (E-H). In the control DRG L2 are present two perikarya immunoreactive to NOS but immunonegative to SP and one perikaryon immunoreactive to these substances (I-L). In the testosterone-affected DRG L2 only one perikaryon immunoreactive to NOS but immunonegative to $\mathrm{SP}$ is visible (M-P).

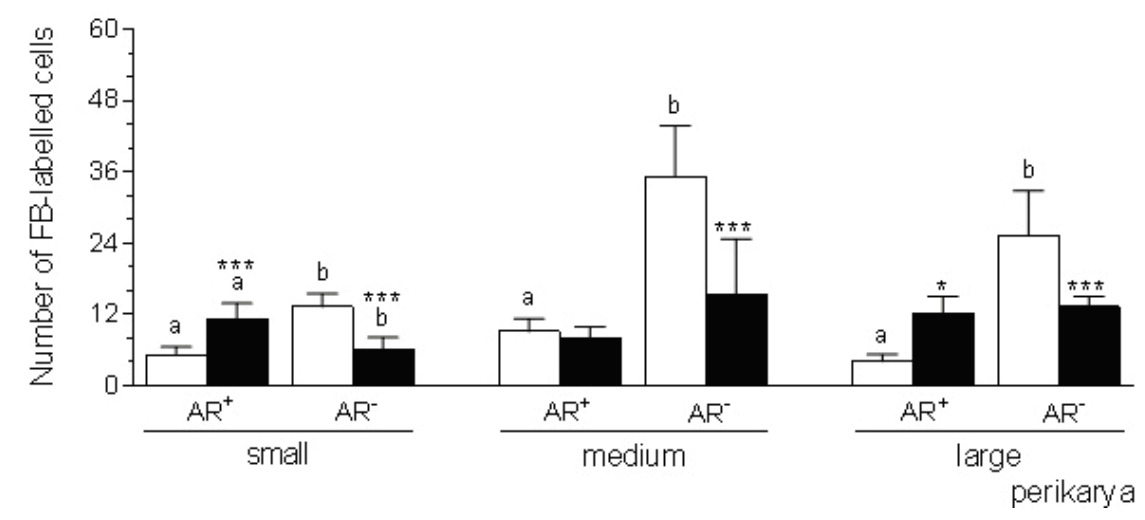

Fig. 6. Mean $( \pm S D$ ) numbers of small, medium and large ovarian perikarya immunoreactive to $A R$ as well as immunonegative to $A R$ in the DRGs Th16-L5 of the control (open bars) and testosterone-injected (solid bars) gilts. Different letters $(a, b)$ indicate differences $(\mathrm{P}<0.05-0.001)$ among the particular neuronal populations within the control or experimental groups; $* \mathrm{P}<0.05$, $* * * \mathrm{P}<0.001 \quad-$ indicate difference between both groups for the same neuronal population.

\section{Discussion}

We show that long-term testosterone treatment of adult gilts results in alterations in the morphological and immunochemical organization of the DRGs ovarian neurons.

Our earlier studies demonstrate that long-term testosterone administration in gilts led to a decrease in the total population of ovarian neurons in the CaMG (Jana et al. 2013b), PCG (Jana et al. 2014) and SChGs (Jana et al. 

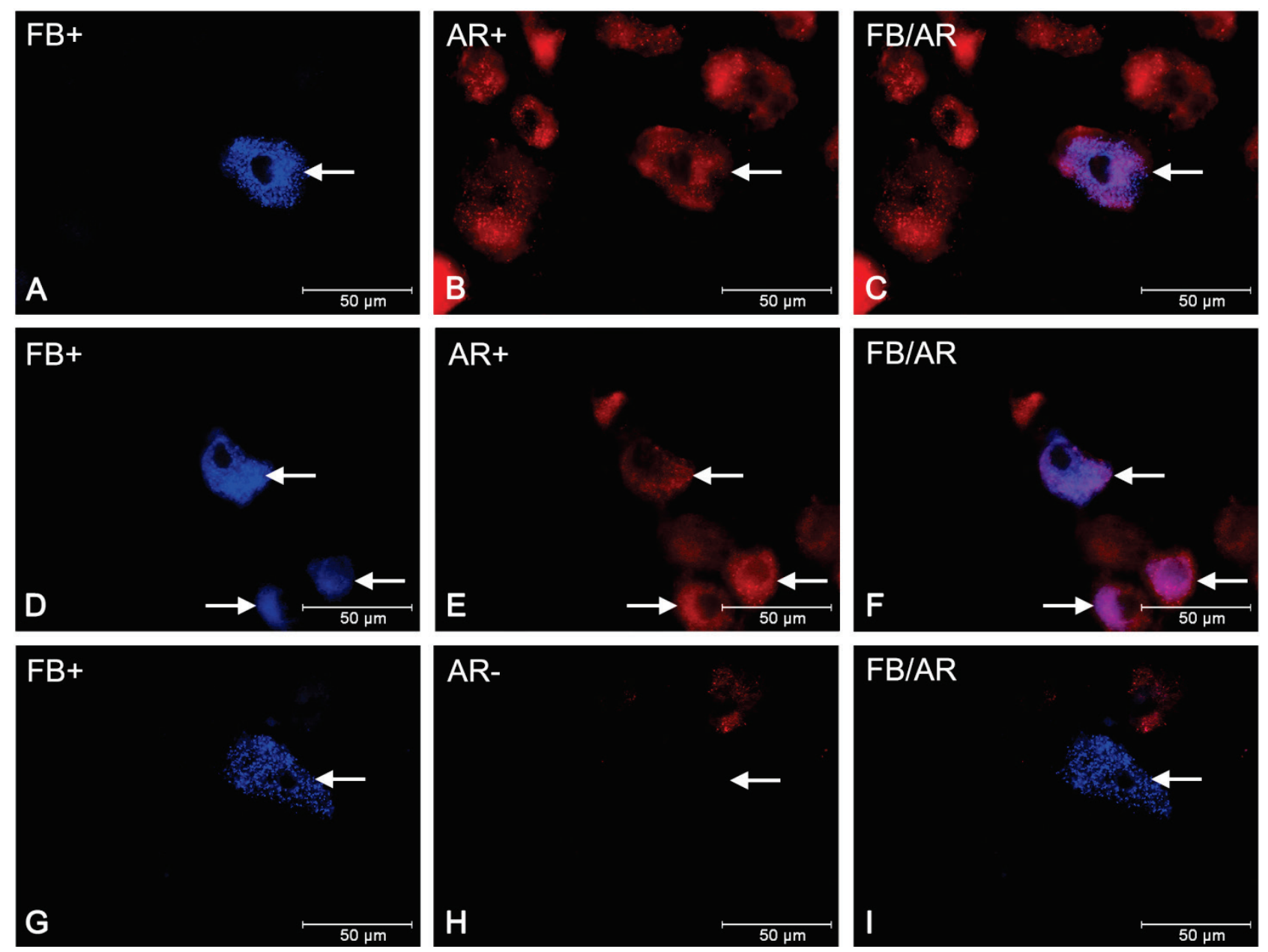

Fig. 7. Fluorescent micrographs showing $A R-(B, C, E, F)$ immunoreactivity in the DRGs of the control (A-C) and testosterone-injected (D-F) gilts after injections of Fast Blue (FB) into the ovaries. The arrow indicates FB-positive ovarian perikaryon containing AR. Photographs $\mathrm{C}$ and $\mathrm{F}$ have been created by digital superimposition of two color channels; FB-positive (blue) and AR-positive (red). Visible one perikaryon expressing AR in the $L 3$ DRG of the control gilt (A-C). In the testosterone-affected DRG L3 three AR-positive perikarya occur (D-F). Negative control for AR (G-I).

2015). The present findings also show the reduction in the total number of ovarian perikarya, including medium ones, in the DRGs of testosterone-injected gilts. We suppose that this situation was not directly caused by the elevated testosterone level. The above statement may partly result from the present study, in which the rise in the total set of AR-positive ovarian perikarya in the DRGs of testosterone-treated gilts was revealed. Moreover, in the testosterone group a decrease in the number of medium-sized perikarya was convergent with the unchanged number of these perikarya positive to AR. We also revealed the greater populations of small and large ovarian perikarya positive to $\mathrm{AR}$, and a lack of changes in the numbers of these structures. Literature data also show that androgens maintain and stimulate somata size and growth, and that castration or androgens did not affect the vitality of TH-, nNOS- and VIP-IR perikarya in male rat PG (Keast and Saunders 1998, Melvin et al. 1988, Melvin et al. 1989, Meusburger and Keast 2001, Purves-Tyson et al. 2007). Thus, the drop in the population of the ovarian perikarya in the DRGs of testosterone-administered gilts (present study) could be caused by increased estradiol-17 $\beta$ level in the peripheral blood, which resulted from aromatization of the injected testosterone. The sets of ovarian perikarya lowered in the DRGs (Jana et al. 2012), as well as the SChGs (Koszykowska et al. 2011a), CaMG (Koszykowska et al. 2011b) and PCG (Jana et al. 2013a) of long-term estradiol-17 $\beta$-treated gilts. The increased estradiol-17 $\beta$ level in the gilts used in the present study might be accompanied by down-regulated estrogen receptors (ERs) expression in the DRGs ovarian perikarya, but this is not yet known. Therefore, the diminution in the ERs content in the perikarya could markedly limit the direct 
estradiol-17 $\beta$ effects promoting the survival of these structures, leading to their loss. The decreased sets of ovarian perikarya expressing ERs were revealed in the DRGs (Jana et al. 2012, Sohrabji et al. 1994), SChGs (Koszykowska et al. 2011a) and PCG (Jana et al. 2013a) exposed to estrogens. The decreased set of ovarian perikarya in the testosterone-receiving gilts (present study) may also result from the reduced expression of nerve growth factor (Kaur et al. 2007, Pieretti et al. 2013, Sohrabji et al. 1994) and insulin-like growth factor-1 and/or its receptor (Böttner and Wuttke 2006) under the influence of the elevated testosterone and estradiol-17 $\beta$ levels.

The populations of ovarian perikarya in the gilt DRGs L2-L4 were decreased after testosterone administration, and these structures were not present in Th16. As mentioned earlier, we also found a drop in the number of medium, but not small and large ovarian perikarya. In response to testosterone injections a lower population of ovarian perikarya was found in the central regions of DRGs. These changes are partly in line with findings revealed in the DRGs of estradiol-17 $\beta$-treated pigs (Jana et al. 2013a), as well as in the porcine CaMG after testosterone (Jana et al. 2013b) and estradiol-17 $\beta$ (Koszykowska et al. 2011b) injections. Taking into consideration literature data (Jana et al. 2013b, Koszykowska et al. 2011b, Majewski et al. 2002, Taleghany et al. 1999) we suppose that changes in the distribution of ovarian perikarya in the DRGs of testosterone-treated gilts might result from elevated testosterone and estradiol-17 $\beta$ concentrations, and differentiated AR and/or ERs expression in different size classes of neurons.

In the DRGs Th16-L5 of testosteroneadministered gilts we determined the reduction in the populations of ovarian perikarya coded SP/CGRP, $\mathrm{SP} / \mathrm{PACAP}$ and $\mathrm{SP} / \mathrm{nNOS}$, and perikarya negative to SP but reactive to nNOS, as well as an increase in the population of perikarya reactive to SP but negative to CGRP. These findings are in agreement with studies showing a drop in the numbers of ovarian perikarya expressing the above-given substances in the gilt DRGs (Jana et al. 2012) and in the population of CGRP-IR neurons in the rat female lumbar DRGs (Yang et al. 1998) exposed to estradiol-17 $\beta$. In turn, in the PCG of testosterone-treated gilts the number of ovarian perikarya coding vesicular acetylcholine transporter (VAChT)/nNOS was reduced, while the populations of ovarian perikarya expressing SOM, VIP or dopamine $\beta$-hydroxylase but not VAChT were upregulated (Jana et al. 2014). In contrast to the present study, the administration of testosterone in gilts led to a decrease in the numbers of ovarian perikarya containing GAL in the CaMG (Jana et al. 2013b) and SChGs (Jana et al. 2015). It may be assumable that the effects of testosterone and estradiol-17 $\beta$ on sensory neurons are partly dependent on their chemical coding (present study), and may result from varied density and the cellular location of AR and ERs in the particular sets. The co-expression of these receptors and particular substances in the neurons of DRGs was not estimated in our study. As mentioned earlier, the male rat DRGs neurons possess AR and CGRP (Keast and Gleeson 1998), and PG neurons are simultaneously positive to AR and VIP, TH or nNOS (Keast and Saunders 1998, Purves-Tyson et al. 2007, Schirar et al. 1997). ERs are present in CGRP-, SP- and PACAP-IR neurons of the DRGs projecting to the uterine cervix in rats (Mowa and Papka 2004, Papka and Mowa 2003) and in nNOS-positive parasympathetic PG neurons of male rats (Purves-Tyson et al. 2007). Exposition of rats to estradiol-17 for 4 days up-regulated the synthesis rate of SP and CGRP (Mowa and Papka 2004, Papka and Mowa 2003), while long-term treatment with estradiol-17 $\beta$ down-regulated the expression of $\beta$-preprotachykinin mRNA encoding SP in the DRGs (Liuzzi et al. 1999). Data explaining the molecular mechanism of changes in the chemical coding of neurons in response to steroid hormones are very limited. It was only suggested by Meusburger and Keast (2001) that testosterone, through AR, may affect neuronal gene expression in cholinergic neurons. Existing data show that the exposure of rat DRG neurons to estradiol-17 $\beta$ led to the phosphorylation of cyclic AMP response-element binding protein (CREB), which mediates transcriptional regulation in sensory neurons (Purves-Tyson and Keast 2004).

As found in the present study, the treatment of gilts with testosterone led mainly to a down-regulation in the numbers of ovarian perikarya expressing SP and/or CGRP, PACAP, nNOS in the DRGs Th16-L5. Moreover, according to our unpublished observations these changes were accompanied with decreased populations of nerve fibers immunoreactive to all above-mentioned substances in ovaries of gilts from which the DRGs were obtained to the present study. Reduction of the fibers has been found within ground plexus and around blood vessels, while CGRP-IR fibers were not present in vicinity of the follicles. All the data may suggest that these changes may 
underlie disturbances in neuronal transmission from the ovary to the spinal cord and in antidromic regulation of the ovarian cells. Earlier reports show the involvement of $\mathrm{SP}, \mathrm{CGRP}$ and nNOS in the transmission of nociceptive information induced by noxious stimuli (Meller and Gebhardt 1993, Yang et al. 1998). In addition, under physiological conditions PACAP and GAL regulate follicular growth (Majewski et al. 2002, Morelli et al. 2008), and these peptides, as well as SP, CGRP and nNOS, modulate the ovarian blood flow and steroidogenesis (Debeljuk 2006, Majewski 1997). It is worth mentioning that receptors for SP (Löffter et al. 2004), GAL (Pang et al. 1999) and PACAP (Morelli et al. 2008) are expressed in the ovarian cells.

It is worth adding that injections of $1000 \mu \mathrm{g}$ of testosterone twice a day in gilts led to the following changes in the concentrations of steroid hormone in the peripheral blood as compared to the controls: testosterone levels were increased on all days of the study (approximately 4-5 fold), except for days 2, 12 and 35-37; estradiol-17 $\beta$ levels were increased on days 4-14 and 21-29 (approximately 1.6 fold); estrone levels were decreased on days 8-11, 15, 16, 18, 19, 29-32, 37 and 38; androstendione levels did not markedly differ between either group (Jana et al. 2013b). The level of testosterone revealed in gilts after the application of the above dose of testosterone was similar to values of the total and bioavailable testosterone appearing in the peripheral blood of women with bilateral mononuclear adrenal hyperplasia (Goodarzi et al. 2003). Moreover, the free androgen index is about 5-fold higher in women with PCOS than in controls (Panidis et al. 2005). The levels of testosterone in testosterone-injected gilts (our study) are also in agreement with those determined in the blood of gilts with ovarian cysts (Fitko et al. 1998).

In conclusion, our study shows that long-term testosterone treatment of adult gilts results in alterations in both the spatial and neurochemical organization pattern of ovary sensory innervation. The data suggest that hyperandrogenism may regulate the transmission of sensory modalities from the ovary to the spinal cord, and antidromic regulation of the ovarian structure functions by affecting the ovary supplying DRGs neurons. Although our study concentrated only on ovarian DRG Th16-L5 perikarya, testosterone treatment could affect also the DRG neurons supplying other urogenital organs and intestine, due to the fact that those DRG neurons may express receptors for steroid hormones. This question needs further investigations.

\section{Conflict of Interest}

There is no conflict of interest.

\section{Acknowledgements}

This work was supported by the State Committee for Scientific Research (grant no. 30801832/1503) and statutory research funds of the Polish Academy of Sciences.

\section{References}

BOSSOWSKA A, CRAYTON R, RADZISZEWSKI P, KMIEC Z, MAJEWSKI M: Distribution and neurochemical characterization of sensory dorsal root ganglia neurons supplying porcine urinary bladder. $J$ Physiol Pharmacol 60: 77-81, 2009.

BÖTTNER M, WUTTKE W: Chronic treatment with physiological doses of estradiol affects the GH-IGF-1 axis and fat metabolism in young and middle-aged ovariectomized rats. Biogerontology 7: 91-100, 2006.

CARMINA E: Ovarian and adrenal hyperandrogenism. Ann N Y Acad Sci 1092: 130-137, 2006.

DEBELJUK L: Tachykinins and ovarian function in mammals. Peptides 27: 736-742, 2006.

FITKO R, JANA B, KUCHARSKI J, SOBCZAK J: Changes in periestrous hormonal profile in blood of gilts with different thyroid function and ovarian cysts. Polish J Vet Sci 1: 3-9, 1998.

GOODARZI MO, DAWSON DW, LI X, LEI Z, SHINTAKU P, RAO CV, VAN HERLE AJ: Virilization in bilateral macronodular adrenal hyperplasia controlled by luteinizing hormone. J Clin Endocrinol Metab 88: 73-77, 2003.

HAMILL RW, SCHROEDER B: Hormonal regulation of adult sympathetic neurons: the effects of castration on neuropeptides Y, norepinephrine, and tyrosine hydroxylase activity. J Neurobiol 21: 731-742, 1990.

HILL KE, SCOTT-MONCRIEFF JC, KOSHKO MA, GLICKMAN LT, GLICKMAN, NW, NELSON RW, BLEVINS WE, OLIVER JW: Secretion of sex hormones in dogs with adrenal dysfunction. J Am Vet Med Assoc 226: 556-561, 2005. 
JANA B, KUCHARSKI J, ZIĘCIK AJ: Effect of intrauterine infusion of Escherichia coli on hormonal patterns in gilts during the oestrous cycle. Reprod Nutr Dev 44: 37-48, 2004.

JANA B, LATA M, BULC M, CAŁKA J: Long term estradiol-17 $\beta$ administration changes population of the dorsal root ganglia neurons innervating the ovary in the sexually mature gilts. Neuropeptides 46: 157-165, 2012.

JANA B, PALUS K, CZARZASTA J, CAŁKA J: Long-term estradiol-17 $\beta$ administration changes population of paracervical ganglion neurons supplying the ovary in adult gilts. J Mol Neurosci 50: 424-433, 2013 a.

JANA B, RYTEL L, CZARZASTA J, CAŁKA J: Reduction of the number of neurons in the caudal mesenteric ganglion innervating the ovary in sexually mature gilts following testosterone administration. J Neuroendocrinol 25: 826-838, 2013b.

JANA B, CAŁKA J, BULC M, CZARZASTA J: Long-term testosterone administration affects the number of paracervical ganglion ovary-projecting neurons in sexually mature gilts. Neurosci Res 83: 89-96, 2014.

JANA B, CAŁKA J, RYTEL L, CZARZASTA J: Morphological and neurochemical characterization of the ovarian sympathetic chain ganglia perikarya in testosterone-treated sexually matured pigs. Ann Anat 202: 28-35, 2015.

KANJHAN R, OSBORNE PB, OUYANG M, KEAST JR: Postnatal maturational changes in rat pelvic autonomic ganglion cells: a mixture of steroid-dependent and -independent effects. J Neurophysiol 89: 315-323, 2003.

KAUR G, JANIK J, ISAACSON LG, CALLAHAN P: Estrogen regulation of neurotrophin expression in sympathetic neurons and vascular targets. Brain Res 1139: 6-14, 2007.

KEAST JR, GLEESON RJ: Androgen receptor immunoreactivity is present in primary sensory neurons of male rats. Neuroreport 9: 4137-4140, 1998.

KEAST JR, SAUNDERS RJ: Testosterone has potent, selective effects on the morphology of pelvic autonomic neurons which control the bladder, lower bowel and internal reproductive organs of the male rat. Neuroscience $\mathbf{8 5}$ : 543-556, 1998.

KOSZYKOWSKA M, CAŁKAJ, GAŃKO M, JANA B: Long-term estradiol-17 $\beta$ administration reduces population of neurons in the sympathetic chain ganglia supplying the ovary in adult gilts. Exp Mol Pathol 91: 353-361, $2011 \mathrm{a}$.

KOSZYKOWSKA M, CAŁKA J, SZWAJCA P, JANA B: Long-term estradiol-17 $\beta$ administration decreases the number of neurons in the caudal mesenteric ganglion innervating the ovary in sexually mature gilts. $J$ Reprod Dev 57: 62-71, 2011 b.

LIUZZI FJ, SCOVILLE SA, BUFTON SM: Long-term estrogen replacement coordinately decreases trkA and $\beta$-PPT mRNA levels in dorsal root ganglion neurons. Exp Neurol 155: 260-267, 1999.

LÖFFTER S, SCHULZ SP, HUNT SP, SPANEL-BOROWSKI K: Increased formation of corpora lutea in neurokinin 1-receptor deficient mice. Mol Reprod Dev 68: 408-414, 2004.

LUO H, LIU J, KANG D, CUI S: Ontogeny of estrogen receptor alpha, estrogen receptor beta and androgen receptor, and their co-localization with Islet-1 in the dorsal root ganglia of sheep fetuses during gestation. Histochem Cell Biol 129: 525-533, 2008.

MAJEWSKI M: Afferent and efferent innervation of the porcine ovary-sources of origin and chemical coding (in Polish). Acta Acad Agricult Techn Olst, Veterinaria, supplementum B 24: 3-123, 1997.

MAJEWSKI M, HEYM C: The origin of ovarian neuropeptide Y (NPY)-immunoreactive nerve fibres from the inferior mesenteric ganglion in the pig. Cell Tissue Res 26: 591-596, 1991.

MAJEWSKI M, KALECZYC J, WĄSOWICZ K, BOSSOWSKA A, GONKOWSKI S, KLIMASCHEWSKI L: Characterization of afferent and efferent galanin-containing nerve fibres in the porcine ovary. Folia Histochem Cytobiol 3: 261-268, 2002

MELLER ST, GEBHARDT GF: Nitric oxide (NO) and nociceptive processing in the spinal cord. Pain 52: 127-136, 1993.

MELVIN JE, HAMILL RW: Androgen-specific critical periods for the organization of the major pelvic ganglion. J Neurosci 9: 736-742, 1989.

MELVIN JE, MCNEILL TH, HAMILL RW: Biochemical and morphological effects of castration on the post organizational development of the hypogastric ganglion. Brain Res 466: 131-139, 1988.

MEUSBURGER S, KEAST JR: Testosterone and nerve growth factor have distinct but interacting effects on structure and neurotransmitter expression of adult pelvic ganglion cells in vitro. Neuroscience 108: 331-340, 2001. 
MORELLI MB, BARBERI M, GAMBARDELLA A, BORINI A, CECCONI S, CATICCHIO G, CANIPARI R: Characterization, expression, and functional activity of pituitary cyclase-activating polypeptide and its receptors in human granulosa-luteal cells. J Clin Endorinol Metab 93: 4924-4932, 2008.

MOWA CN, PAPKA RE: The role of sensory neurons in cervical ripening: effects of estrogen and neuropeptides. J Histochem Cytochem 52: 1249-1258, 2004.

PANG L, GRAZIANO M, WANG S: Membrane cholesterol modulates galanin-GaIR2 interaction. Biochemistry 14: 12003-12011, 1999.

PANIDIS D, FARMAKIOTIS D, KOLIAKOS G, ROUSSO D, KOURTIS A, KATSIKIS I, ASTERIADIS C, KARAYANNIS V, DIAMANTI-KANDARAKIS E: Comparative study of plasma ghrelin levels in women with polycystic ovary syndrome, in hyperandrogenic women and in normal controls. Hum Reprod 20: 2127-2132, 2005.

PAPKA RE, MOWA CN: Estrogen receptors in the spinal cord, sensory ganglia, and pelvic autonomic ganglia. Int Rev Cytol 231: 91-127, 2003.

PIERETTI S, MASTRIOTA M, TUCCI P, BATTAGLIA G, TRABACE L, NICOLETTI F, SCACCIANOCE S: Brain nerve growth factor unbalance induced by anabolic androgenic steroids in rats. Med Sci Sports Exerc 45: 29-35, 2013.

PURVES-TYSON TD, KEAST JR: Rapidactions of estradiol on cyclic AMP response-element binding protein phosphorylation in dorsal root ganglion neurons. Neuroscience 129: 629-637, 2004.

PURVES-TYSON TD, ARSHI MS, HANDELSMAN DJ, CHENG Y, KEAST JR: Androgen and estrogen receptormediated mechanisms of testosterone action in male rat pelvic autonomic ganglia. Neuroscience 148: 92-104, 2007.

SCHIRAR A, CHANG C, ROUSSEAU JP: Localization of androgen receptor in nitric oxide synthase- and vasoactive intestinal peptide-containing neurons of the major pelvic ganglion innervating the rat penis. J Neuroendocrinol 9: 141-150, 1997.

SINGH P, DELEON F, ANDERSON R: Steroid cell ovarian neoplasm, not otherwise specified: a case report and review of the literature. Case Rep Obstet Gynecol 2012: 253152, 2012.

SOHRABJI F, MIRANDA RC, TORAN-ALLERAND CD: Estrogen differentially regulates estrogen and nerve growth factor receptor mRNAs in adult sensory neurons. $J$ Neurosci 14: 459-471, 1994.

SWINDLE MM, MAKIN A, HERRON AJ, CLUBB FJ JR, FRAZIER KS: Swine as models in biomedical research and toxicology testing. Proc Natl Acad Sci USA 109: 16612-16617, 2012.

SZULAŃCZYK-MENCEL K, RZASA A, BIELAS W: Relationships between ovarian cysts and morphological and hormonal state of ovarian cortex in sows. Anim Reprod 121: 273-278, 2010.

TALEGHANY N, SARAJARI, S, DONCARLOS LL, GOLLAPUDI L, OBLINGER MM: Differential expression of estrogen receptor alpha and beta in rat dorsal root ganglion neurons. J Neurosci Res 5: 603-615, 1999.

VALLCANERAS SS, CASAIS M, DELGADO SM, FILIPPA V, MOHAMED F, SOSA Z, RASTRILLA AM: Androgen receptors in coeliac ganglion in late pregnant rat. Steroids 74: 526-534, 2009.

VALLCANERAS SS, CASAIS M, ANZULOVICH AC, DELGADO SM, SOSA Z, TELLERIA CM, RASTRILLA AM: Androstenedione acts on the coeliac ganglion and modulates luteal function via the superior ovarian nerve in the postpartum rat. J Steroid Biochem Mol Biol 125: 243-250, 2011.

VARMA T, PANCHANI R, GOYAL A, MASKEY R: A case of androgen-secreting adrenal carcinoma with nonclassical congenital adrenal hyperplasia. Indian J Endocrinol Metab 17: 243-245, 2013.

YANG Y, OZAWA H, LU H, YURI K, HAYASHI S, NIHONYANAGI K, KAWATA M: Immunocytochemical analysis of sex differences in calcitonin gene-related peptide in the rat dorsal root ganglion, with special reference to estrogen and its receptor. Brain Res 791: 35-42, 1998. 